\title{
Bioremediation Mariculture in Zanzibar, Tanzania: A Viability Assessment of Using Bath Sponge and Pearl Oyster Farms to Filter Highly Polluted Waters in the Zanzibar Channel
}

\author{
Hayley Catherine Oakland*, Marine Biology
}

\begin{abstract}
Bioremediation of polluted water off the coastline of the urban center of ZanzibarStone Town, Unguja-was assessed through bath sponge and pearl oyster mariculture feasibility. In recent years, scientific analysis has shown a wastewater pollution distribution in conjunction with the water circulation created by the East African Counter Current and its harmful ramifications for the fringing ecosystems. As a proposed mitigation to this issue and in following the experimental examples of bioremediation projects around the world, this study tested facets of the filtration abilities of marine sponges and oysters. Both organisms suggested strong pollution filtration abilities. Phosphate concentrations decreased from an average of $3.93 \mu \mathrm{g} / \mathrm{L}$ (micrograms per liter) to 1.33 and $1.73 \mu \mathrm{g} / \mathrm{L}$ for sponges and oysters, respectively. Unique capabilities of each organism were displayed in the experiments in that the marine sponges visibly eliminated the turbidity level in the 36-hour study period while the marine oysters were suggested to chemically convert the dissolved nitrates through the tested increase in ammonium concentration from an average of $4.01 \mu \mathrm{g} / \mathrm{L}$ in the contaminated water to an average replicate concentration of $21.5 \mu \mathrm{g} / \mathrm{L}$. The respective mariculture techniques were examined along with management logistics to assess the viability of implementing mariculture for pollution remediation. It was concluded that the mariculture techniques could be feasibly established by carefully collaborating with the nature of the pollution distribution, the consultation and aid of private and governmental organizations and adjacent villages, and further background scientific research.
\end{abstract}

*Hayley Oakland is a senior in the departments of Marine Biology and Environmental Science. In 2013 she studied coastal ecology and natural resource management in Zanzibar, Tanzania, where she completed this research in collaboration with local organizations. She plans to continue to research restoration and conservation in the marine environment.

Please direct correspondence to hoakland@uoregon.edu. 


\section{INTRODUCTION}

Polluted seawater is an undeniable and indisputable situation for active ports around the world. Stone Town, Zanzibar is an established World Heritage site where visitors from around the world come to see history, culture and biodiversity concentrated in one place, but it is also a polluted port that is further desecrated by the outflow of raw sewage pipelines and wastewater runoff directly into the waterfront. Numerous previous studies have shown that the sewage and wastewater runoff in the city of Stone Town have directly increased the concentrations of harmful nutrients and biological macromolecules along the town's coastline (Van Bruggen 1990, Anderson 1994, Shunula and Ngoile 1995, Mmochi 1996, Moynihan 2011), however, little has been done in the way of mitigating these pollutants. Unfortunately, most of this pollution comes from the stress of the ever-increasing population size of the urban center of Zanzibar. With this the outcome of Zanzibar's population growth must be managed to prevent any further damage to the health of both the surrounding ecosystems and communities. The cleanliness of the seawater proves essential to the habitability of the entire biosphere and must be addressed.

An extremely small proportion of industries and individual households are even connected to the sewage line, making runoff a substantial issue, especially in the rainy seasons (during which this study takes place). Wastewater runs off into the seawater along the coast, highly concentrated at the sewage outflows (Mmochi 1996), carrying water-borne illnesses and harmful toxins to coral reef and mangrove ecosystems, epicenters of ocean fertility and health, and the main source of livelihood for Zanzibaris. Controlling this disseminated source is seemingly unfeasible, but it can be remediated with an ecosystem-based (EBM) and integrated coastalzone management approach (ICZM).

It is critical to act before this problem worsens. Luckily, there is still life in the ecosystems off of Stone Town, but with the continuance of such a prominent and unrelenting stressor, that life is not likely to remain. EBM and ICZM take into account the whole ecosystem affected and search for solutions to solve the entirety of the issue for the whole system (Mohammad, personal communication; Progress in Integrated Coastal Management 2000). In the case of this study, the mariculture also employs natural means of solving the problem. The proposed action for the mitigation of sewage-ridden water off of Stone Town, Zanzibar is zooremediation through bivalve molluscs and sponge porifera.

Zooremediation is progressively utilized as a solution to polluted waters all over the world, both marine and fresh, which employs organisms from various evolutionarily advanced positions, utilizing their natural biological processes to remediate contaminated water. Such species have varying abilities to filter, oxygenate and decontaminate the surrounding water column (Gifford et al 2006). Sponges and oysters coexist in the intertidal zone, the shallowest and most diverse ocean habitat, making them ideal filtration partners to holistically support that keystone ecosystem. Tangentially, working together allows that neither is overloaded while each contributes its unique individual abilities to aid humans in remediation of the damage continually done to the marine ecosystem. 
The choice of these invertebrates arises from an expansive research base that has proven these seemingly evolutionarily simple creatures to be remarkable filter feeders, thriving off of what other species, including our own, process as biotoxins (Gifford et al 2005, Longo et al 2010, Rittschof and McClellan-Green 2005). These biotoxins consist both of the direct effluents and nutrients dissolved in the mixing of seawater and sewage such as nitrates, phosphate and ammonium, but also of phyto- and zooplankton and bacteria: the organisms in the water column that exist naturally to a certain extent but become over-populated and invasive with the introduction of high concentrations of these nutrients. High populations increase the turbidity of the water (amount of dissolved particles affecting the water's transparency), which prevents keystone-photosynthesizing organisms such as seagrass and algae (including the zooxanthallae algae in coral) from accessing the essential sunlight source. Bacteria blooms cause anoxic conditions in the water by depleting the dissolved oxygen in the water when metabolizing the accumulating nutrients. Consequentially, the seawater affected becomes highly noxious to the ecosystems contained, leading to entire 'dead zones' (NOAA 2013). The specific fauna in question for the remediation of these issues are bath sponges and pearl oysters, two organisms that naturally maintain the ocean's biochemical stability through filtering plankton and bacteria out of seawater.

Sponges and oysters similarly get their sustenance by sucking in ocean water, taking out microorganisms present, and spewing back out seawater rid of these components. Sponges in the phylum porifera have a specialized pore called the ostia that is able to draw in water through the action of many choanocytes, custom cells that pump water, creating a current in the surrounding fluid (Milanese et al 2003). This current pulls in the seawater surrounding the sponge containing bacteria, phytoplankton and zooplankton food sources, in addition to suspended particles, which is indiscriminately filtered through the animals' mesohyl matrices. These organisms have a uniquely strong retention and accumulation ability and can filter their entire surrounding water column in 24 hours (Longo et al, Gifford et al).

Similarly, oysters, which in the class of molluscs called bivalves, draw in water to filter through their stomachs and gills. This process, analogous to the sponges' choanocytes, is generated by cilium on the oysters' gill cells (Raj 2008). Their food source comes from microalgal nanoplankton, however, they are indiscriminate in filtering all particulate matter (Gifford et al 2005). Though they do take nutrients from the water column through their consumption of phytoplankton, they do release some as well (Saito 2012.) In this way, another bioaccumulator must be near to the oyster to have holistic biopollutant filter-feeding success.

Sponges and oysters are effective together because of their ability to collaborate in the filtration of most pollutants, but also to uniquely filter what the other cannot. Sponges are proposed as the nitrogen repository here to prevent the combination of edibility and wastewater filtration. In this way, sponges are proven to be highly effective at bioaccumulation of ammonia and their ability to accumulate dissolved biological particles at a high rate (Gifford et al 2006, Longo et al 2010), creating an ideal coexistence with oysters. 
Neither organism, nor the ecosystems involved can tolerate overexposure to pollutants, and therefore a careful placement must be assessed to ensure adequate filtration of the pollutants without harming these animals or ecosystems. Variability in pollution concentrations can affect the abilities of the organisms to effectively filter (Souza et al 2013), so careful placement of the proposed mariculture will allow the organisms to effectively filter without vulnerability. Similarly, these organisms cannot become invasive to the ecosystems to which they are introduced, though management will be inherent given that these organisms are currently cultivated through mariculture practices around the island (Vauterlaus, personal communication; IMS), and that is the method proposed for implementation. Supervision and investment could be provided by the Department of Environment of the Revolutionary Government of Zanzibar. In this way, the use of pearl oysters and bath sponges to filter the water off of Zanzibar could be carefully designed to effectively aid in the port's pollution situation.

\section{STUDY AREA}

Farming methods are observed in the villages of Jambiani and Fumba, Unguja. The contaminated sample water is collected from Maruhubi, Unguja and the water off of the Institute of Marine Science. The 'clean' seawater is collected from Fumba, Unguja. The filtration techniques experiments and all water analyses were completed at the Institute of Marine Science, University of Dar Es Salaam, Zanzibar in Stone Town, Unguja. These locations can be found on the map of Unguja Island, Zanzibar in Appendix I, figure 3.

\section{METHODS}

The assessment of the viability and potential success of marine sponge and oyster farming for pollution filtration off of Stone Town is initiated through the observation of the individual farming methods in the respective locations they are practiced, observing the explants (the portion of harvested organism transferred to a new medium for growth). Then, the ability of the bath sponge and pearl oyster species are experimentally analyzed at the Institute of Marine Science laboratories. Finally, the logistical aspect of implementation is evaluated through managerial interviews.

\subsection{FARMING AND ORGANISMS OBSERVATIONS}

The shallow-water bath sponge farm in Jambiani is visited at a low, spring (wider range) tide by foot and snorkel gear. The mariculture apparatus, coexisting species/habitats, and maintenance methods are observed. Local community members are surveyed on their opinions of the mariculture potential, including another MC employee. [Employees remain anonymous.]

The oyster farm in Fumba is observed by boat, using snorkel and free diving techniques with the farmer. Regular maintenance and cultivation processes are observed. Coexisting organisms and adjacent habitats are observed and recorded. The farmer is asked how he collects explants, 
about the process of growth and cultivation, and about the market. Local community members are surveyed on their opinions of the mariculture practice.

\subsection{COLLECTION}

An extremely sharp knife is used to harvest one third of the animal's body volume. (Duckworth et al 2007.) Four species most commonly occurring on the Jambiani intertidal are collected: the 'grey', 'green', 'red-branching', and 'black' species. The sponges are never squeezed given that this may be harmful or even fatal to the organism and its functions. The collected explants are always covered in seawater, and immediately transferred to an oxygenated storage tank upon arrival at the laboratory.

Pearl oysters are collected at a morning spring low tide in Fumba, Unguja. The animals are collected by gently pulling them off the hard surface to which they are attached. A minimum of thirty oysters is needed for the six sample buckets. The oysters are transported in a mesh bag out of water, but immediately transferred to six oxygenated storage buckets.

'Control' seawater is collected from Fumba, Unguja using a large 20-liter bucket. Contaminated seawater is collected from the beach in front of Marahubi ruins, a focal location determined by the Zanzibar Channel current discussion (see Appendix I, figure 3).

\subsection{FILTRATION ABILITIES}

The filtration abilities of the sponges are assessed using the collected sponges from the Jambiani intertidal. The sample specimens are given 36 hours to filter the experimental water column; nothing is added or taken out during the experiment period except oxygenation. The four sponges are placed in a 20-liter bucket filled with 15 liters of contaminated water. During the experiment period, turbidity and particle observations are made at four even intervals.

Oysters are individually able to filter 2 gallons, or about 8 liters of water per hour (Raj 2008) providing that five oysters should effectively filter 2 liters in one hour. Five oysters are placed in each of six 15-liter buckets containing 2 liters of contaminated seawater each. The first five sample oysters are then placed in the sample bucket and a one-hour timer is started. Three sample buckets are run at the same time using this method, therefore repeating the above method two times (for six samples). Observations of the filtration and other activities of the oysters are taken during the sampling period, including the turbidity and movement patterns of the water. After the one-hour trial, the oysters are placed back in their oxygenated holding buckets and the sample water is poured into the respective labeled water bottles.

A 0.5-liter sample of each of the 'contaminated' seawater from Maruhubi and the 'clean' seawater from Fumba are taken. These samples and the trials described above are stored in collection bottles in a $-20^{\circ}$ freezer until they are tested for phosphates and ammonia using a spectrophotometer. These methods are dictated in Parsons et al in the Manual for Seawater Analysis (using the 'alternative' method for ammonium). 


\subsection{MANAGEMENT LOGISITCS}

The implementation of Marine Cultures on Unguja by resident Christian Vauterlaus is analyzed. The logistics of implementation and why he chose Jambiani as a location are inquired. The market for the sponges and economic details are investigated. Finally, the rapport with the local community, how it is kept and what the steps are for future cooperation are explored.

Hamza Rijaal is the representative respondent for the Zanzibar Department of Environment. The zonation of Stone Town in terms of the plans for the sewage and drainage systems is investigated along with the potential for the Department to aid the project.

\section{RESULTS}

\subsection{FARMING TECHNIQUES AND BIODIVERSITY}

The experimental shallow-water sponge farming project in Jambiani, Unguja was analyzed and observed for 4 days. Interviews of the employees and local community members displayed a great interest in the new form of mariculture recently introduced (2008-9) to the small community. The shallow-water farm itself (one of three currently operated by Marine Cultures in the area) was exposed at about 1 meter at low tide (between a spring and neap low tides). It consisted of a 6x6 meter rope system with rows of sponge explants (diagram in Appendix I, figure 6). A high biodiversity of coexisting organisms was evident surrounding the farm. The employees interviewed indicated that the farming was relatively easy and low-maintenance (given the accessibility and tools described above).

A pearl oyster farm at Fumba, Unguja was visited. The farm belongs to a single man who created, cultivates and monitors the farm independently (with the aid of IMS-Jiddawi, personal communication). The farm was accessed by dugout canoe and at a neap low tide the farm was at a depth of 4 meters, reaching 6 meters at a spring high tide. The maintenance of the farm involves checking small pieces of wood or plastic, designed for growing new explants, attached to the main T-shaped line (sketch of farm in Appendix I, figure 7), looking for new explants growing along the main line and transferring them to the mesh baskets, and taking the mesh baskets to the surface to clean off the biofouling, clean out the basket of any trapped or biofouling organisms, check on the growth of young oysters, and clean each oyster. A metal prying tool was used to slightly open the shell without damaging the animal to check on the status of the pearls. High biodiversity of coexisting organisms was evident surrounding the farm.

When asked about the cultivation process, the farmer explained that he gets the oyster explants from a deep reef about $1 \mathrm{~km}$ southwest of the farm and about 15 meters in depth. He explained that there are many oysters at the reef of different species; displaying the two types he grows, which were later identified as Pinctada fucata and Pinctada radiata, the former being more abundant and common in Zanzibar. In response to oyster growth, the farmer explained that it takes a year and a half to grow to maturity and to propagate all four pearls [Farmer to 
remain anonymous]. In the local village, community members responded that they appreciate the income source of pearl farming and the ease of using the employment as a supplement in the local economy.

\subsection{COLLECTION LOGISTICS}

The collection of the seawater samples was partially restricted by the access to transportation and resources for water transport. Containers for seawater collection were small and previously used, possibly leading to partial contamination of the samples. Both organisms were collected at a significant distance from Stone Town (the testing and storage site). Both organisms were easily collected at the respective sites, minimally disturbed, and stored in spacious, oxygenated conditions at the lab.

\subsection{FILTRATION ABILITIES}

The tank containing the sponges was significantly turbid prior to sponge implementation and was relatively transparent by the end of the study. The water in the experimental bucket appeared to be flowing based on the visible movement of the particles towards the sponges, but not discernibly circulating.

The water surrounding the oysters became less turbid over the hour-long filtration period. After 5-7 minutes, all oysters in all trials had opened their shells and were actively filtering. The size of the oysters varied between 5 to $10 \mathrm{~cm}$ in diameter and the degree of shell opening and valve exposure varied between 0.2 to $1.5 \mathrm{~cm}$.

The spectrophotometer tests displayed that for both the sponges and the oysters, the concentration of phosphates decreased significantly (see figure 1). The average concentration of the contaminated water replicates was $3.93 \mu \mathrm{g} / \mathrm{L}$ phosphate (before filtration). After the sponge filtration period, the average phosphate concentration of the sample seawater was $1.33 \mu \mathrm{g} / \mathrm{L}$. Similarly, the oysters decreased the concentration to an average of $1.73 \mu \mathrm{g} / \mathrm{L}$ phosphate. The control seawater sample from Fumba contained $1.86 \mu \mathrm{g} / \mathrm{L}$ phosphate.

The side channel itself is approximately 400 meters long and 20 to 30 meters wide. It includes of a mixture of riffles, pools, and glides. The U.S. Forest Service placed five log jams throughout the side channel (Figure 1, Bonanno et al. 2011). The side channel section remains around 6 degrees Celsius for most of the year and can increase to 16 degrees Celsius during summer months, making it optimal spawning ground and rearing habitat for spring Chinook salmon, bull trout (Salvelinus confluentus), and many other aquatic species and wildlife native to the watershed (Risley et al. 2010). 


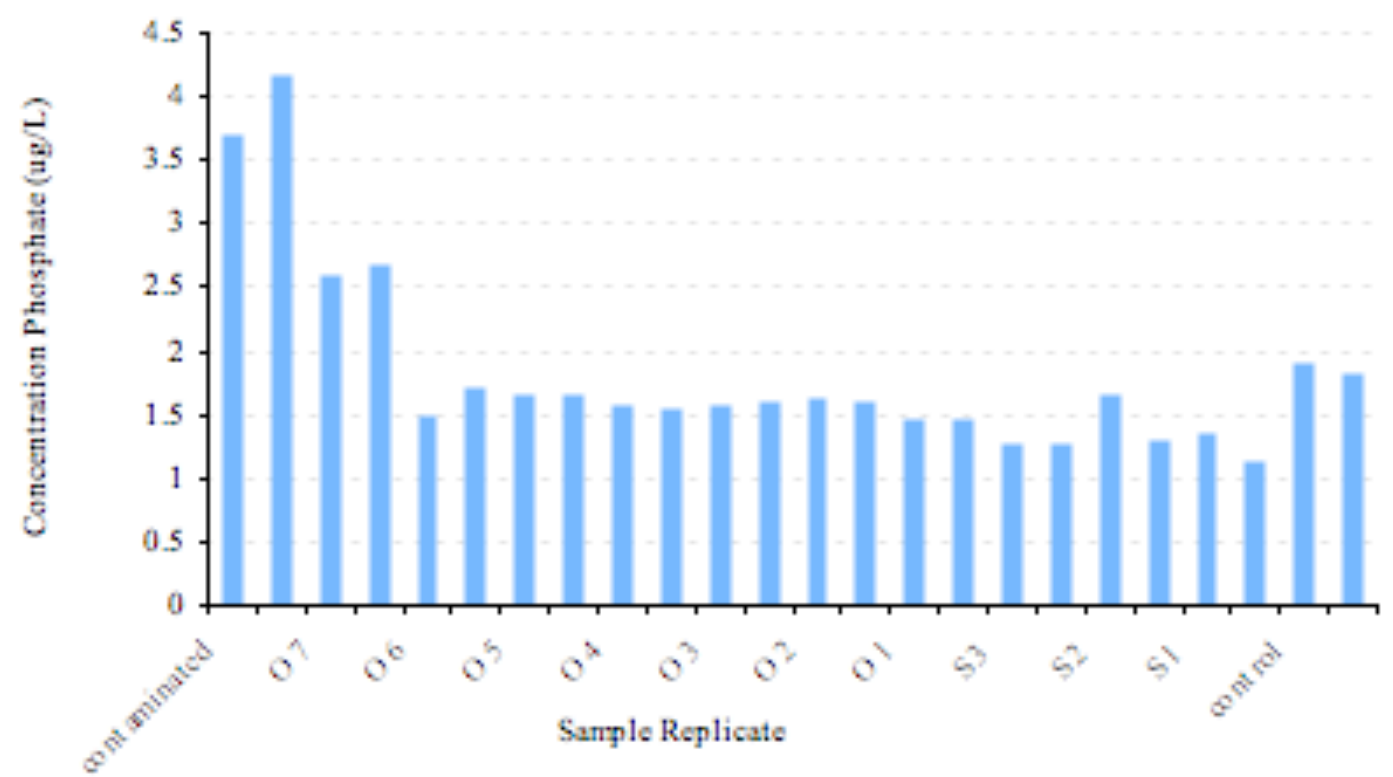

Figure 1. Experimental Phosphate Filtration Results ( $\mathrm{O}=$ oyster; $\mathrm{S}=$ sponge.)

For the ammonium test, (only completed for the oyster samples), the concentration of ammonium increased during the filtration period (see figure 2). The average ammonium concentration of the contaminated water was $4.01 \mu \mathrm{g} / \mathrm{L}$ and went up to an average of $21.5 \mu \mathrm{g} / \mathrm{L}$ after the sample filtration period.

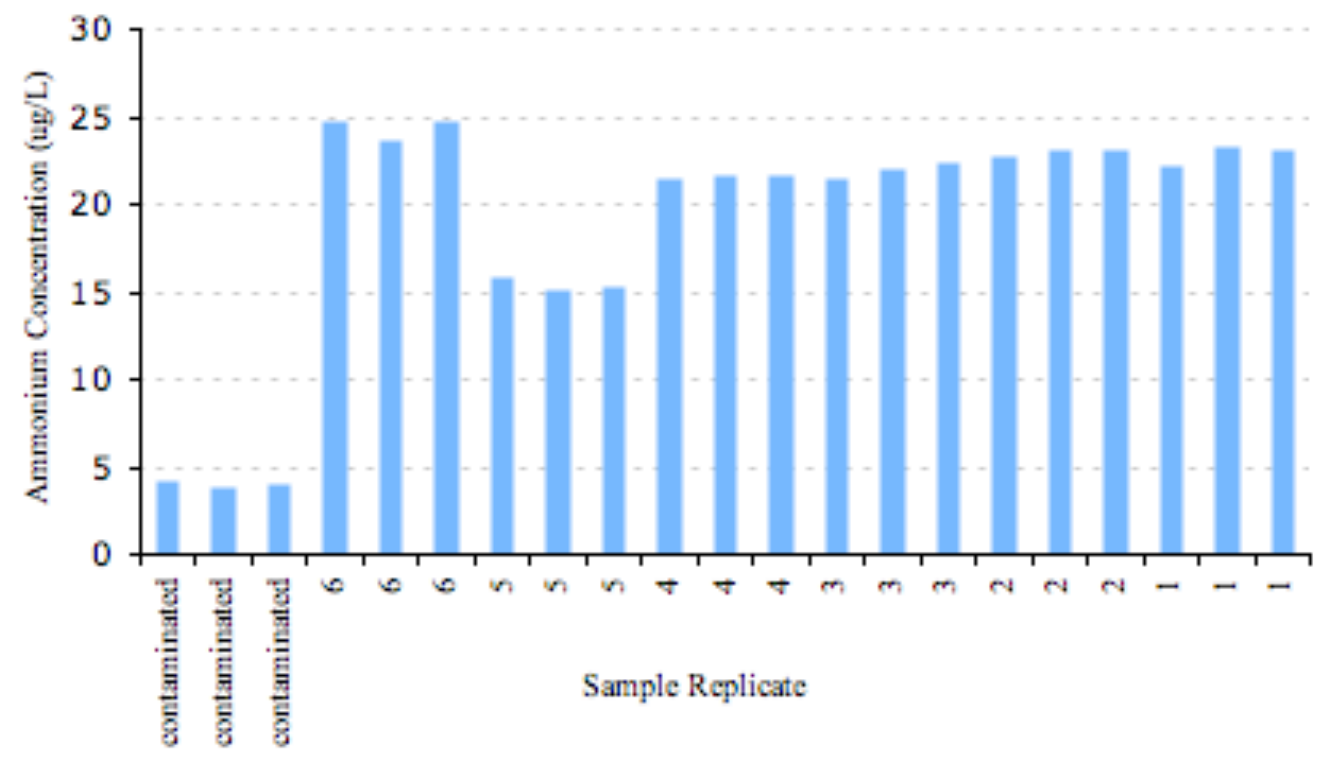

Figure 2. Experimental Oyster Ammonium Filtration Results 


\subsection{MANAGEMENT INTERVIEWS}

Christian Vauterlaus the founder of the Zanzibar branch of Marine Cultures (Vauterlaus, personal communication). After a trip to the South Pacific to study alternative tropical mariculture options, Marine Cultures found a sponge-farming project in Micronesia that had been successful for a highly impoverished place (similar to Zanzibar). Vauterlaus explains that the farming is relatively easy to implement, manage, and sell on a rising world market. Ultimately, Marine Cultures feel they have a connected and successful relationship with the local community. In terms of future prospects, Vauterlaus indicates that after logistics are figured out, Marine Cultures plans to aid locals, other organizations, and government institutions in starting the mariculture where it is wanted and needed, in addition to continuing research on controlling and regulating the growth.

Hamza Rijaal was the respondent for the interview of the Zanzibar Department of Environment position on remediation efforts. He referred to the Zanzibar Environmental Policy created in 1996, which dictates that the department's role is to identify an environmental issue and suggest solutions or alternatives. In explaining the current sewage situation it was revealed that only the originally defined perimeter of Stone Town is a part of the sewage pipe system (see Appendix I, figure 5 map). He explained that the outflow pipes used to go only 10-50 meters off shore, then changed to 150-200 meters with the discovery of high effluent concentrations. The original decision for this system was that the Eastern Africa Counter Current (EACC) would be strong enough to take the polluted water away from human habitation, also creating mixing, and therefore not harm the marine environment to a great extent. He disclosed that this system is not working to keep the harmful effluents from the coast and that the effects are evident at the offshore reefs. Rijaal disclosed that the system often fails when sewage overflows into the streets and becomes runoff, particularly in the rainy season. Similarly, the expanding population is not on this system, but has individual tanks or simply buries the waste. Both of these methods routinely overflow and leak raw sewage and effluents into the runoff onto Unguja's coastline. When asked about the department's role in environmental remediation, he mentioned the Van Bruggen study completed in 1990, which was one of the department's first actions. Upon further prompting, Rijaal indicated that the department is open to aid new projects for remediation of environmental issues.

\section{DISCUSSION}

\subsection{POLLUTION SITUATION}

The growing human population in Stone Town, Unguja undeniably affects the surrounding coastal waters destructively. A large population places significant pressure on the adjacent ecosystems not only through resource use and extraction, but also considerably from the waste associated with resource use. Stone Town's leading issue, both for the health of the ecosystems and the human population, is the effluent pollution leaking straight from sewage and runoff outfalls. A majority of the population is not a part of the sewage system and therefore either have their own tanks or no system at all (Rijaal, personal communication). These systems leak 
into the groundwater and overflow during floods. The sewage treatment that is present in the city only involves the originally defined area of Stone Town (west of Mkapa Road-see Appendix I map, figure 5). This system directs wastewater into a septic tank, through a salt pit and then through out-flowing pipes straight into the coastal water. Unconventional systems are usually just dug pits, which seep the nutrients directly into the groundwater. Even connected to the sewage lines, all of these systems described cause leakage of raw sewage effluents into the watershed, which on a small island such as Zanzibar is directly into the seawater.

Stone Town's population is constantly growing as people come for the opportunities associated with the city, which yields growing pressure on the minimal wastewater plan that exists. The initial decision to allow raw sewage and wastewater to flow directly into the coastal seawater came from the belief that the EACC would solve the problem of pollution. However, the shallow nature of the Zanzibar Channel greatly slows down the strength of the EACC, nullifying its power in transferring and mixing the seawater (Nyandwi, personal communication). The outward jut of Stone Town toward the west creates a slight deflection of the current to the northwest. This detail would perhaps effectively take the hazardous water directly to the deeper portion of the Channel allowing for adequate mixing, but the fringing islands off Unguja's southwest coast complicate the matter. While there is a flow of the current directly northwest, the destination is directly between two of the fringing islands, funneling much of the seawater through the opening (called the 'Great Pass' locally), but deflecting much of the seawater back to Stone Town and the adjacent coastline (see Appendix I, figure 4 schematic, Anderson 1994). Subsequently, the contaminated seawater that is not sufficiently mixed carries harmful nutrients to the coral reef ecosystems of these fringing islands, and back to the human population of the coastline.

The harmful nutrients and effluents include nitrates and phosphates, which facilitate the growth of bacteria and phytoplankton algae. Particularly, nitrogen facilitates the growth of bacteria, which live in the sediment and water column, acting as natural nitrogen fixers for the soil and atmosphere. Although this allows for the growth of the mangrove trees, which obtain their oxygen source from the atmosphere, it creates oxygen-depleted conditions in the surrounding seawater, prohibiting the inhabitance of most marine organisms. Similarly, phytoplanktons thrive off of the phosphate source for growth. The experimental value of 3.93 $\mu \mathrm{g} / \mathrm{L}$ phosphate is high in comparison to the naturally occurring concentration in seawater (Intergovernmental Oceanographic Commission 1993), which is an indication that these nutrients are introduced from an outside source (Parsons et al 1985). This yields an increase in the phytoplankton population and sequentially the zooplankton population, increasing the turbidity of the water (called a 'bloom') and decreasing light access to keystone photosynthesizing organisms, such as the zooxanthallae algae of coral and sea grasses. Consequentially, the upsurge in bacteria and phytoplankton from the excess concentration of nitrates and phosphates, respectively, in the seawater is deleterious to the corresponding ecosystems.

Polluted seawater carries the dissolved nutrients discussed, increasing populations of marine microorganisms as well as the effluents associated with sewage, such as fecal bacteria. 
These bacteria include fecal coliforms (Enterococci and E. coli I), which, dissolved in seawater, can be both an indication of sewage runoff presence (Hanes and Fragala 1967), and can be extremely dangerous to the health of the human population and the ecosystems. A study completed in 2011 to test indications of sewage in the coastal seawater off of Stone Town suggested that there were high concentrations of the bacteria in the water. What was particularly pivotal was the discovery that the concentrations were highest near the outfalls, but were also found on the fringing reefs of Stone Town, such as Bawe and Chapwani (Moynihan 2011). The study additionally shows that the bacteria present are correlated with early stages of eutrophication. It is therefore evident that the sewage runoff is not only reaching the surrounding ecosystems, but also starting to damage them as well.

The turbidity of the seawater observed throughout the study is an indication of these microorganisms and effluent particles present. In the collection of contaminated seawater at Maruhubi, the seawater was highly turbid with a sight distance of less than 1 meter. As reported in the results, this sample water was still distinctly turbid prior to the filtration experiment, indicating that the turbidity of the water in the collection site was not simply due to sediment, as may have been assumed given the collection time at low tide. Suspended particles were observably filtered throughout the experimental interval, however, a total suspended organic carbon analysis could not be completed because of the observation of suspended organisms that would not be filtered and would skew the results, such as barnacle bodies. Nonetheless, the observation was deemed viable in suggesting that most of the suspended material was microorganisms, such as the bacteria and plankton discussed.

The Zanzibar Institute of Marine Science, located in the heart of the area in question, is constantly working to research both the progressing effects on the environment and the potential solutions. However, the previous bioremediation solutions (sea cucumber and algae) have had little success, probably because of the traffic in the area and the strong concentration of pollutants (Jiddawi, personal communication). Perhaps adjusting the placement of the experimental remediation would aid in its success, such as a location far enough down-current from the pollution source to prevent overloading the filtration system, but before the water can reach the vital coral and mangrove ecosystems or the feedback eddy system. Optimizing the location in this way aids in both the protection of the physical structure of the system and the survival of the filtration organisms involved.

\subsection{FILTER-FEEDING CAPABILITIES}

The abilities of oyster bivalves and sponge porifera, powerful filter feeding animals, have been analyzed and explored. Sponges are evolutionarily simple organisms yet they greatly contribute to their ecosystems through the filtration of the water column. This is possible because the ostia pores throughout the body have the ability to filter all particles between 0.1 and 50 micrometers, which provides them the nutrition of phytoplankton and bacteria (Friday 2011). Through this process they accumulate the water's nutrients that these lower-trophic-level microorganisms concentrate in their cells. A particularly important note about the filtration abilities of the sponges is their uniquely high retention rates, which is suggested as up to $80 \%$ of 
the particles they filter (Milanese et al 2003). This presents how incredibly essential sponges are to their ecosystems in retaining the harmful particles to other species as sustenance for their own growth.

The collected sponges of this study proved to be effective filtration systems for the experimental water column. The analysis of phosphate displayed a decrease in the concentration over the study period from $3.93 \mu \mathrm{g} / \mathrm{L}$ of the contaminated sample seawater to $1.33 \mu \mathrm{g} / \mathrm{L}$ (average concentration) of the water after the sponges' filtration period (see figure 1 in section $4.3 \mathrm{~b}$ ). This demonstrates that the sponges are successfully accumulating the phosphate source in the seawater, most likely from the thriving phytoplankton populations. In a study comparing the phosphorus and nitrogen levels with the phytoplankton and bacterioplankton present, a correlation between phosphorus and phytoplankton levels was evident, and a further relationship between phytoplankton and bacterioplankton was present as well (as the bacterioplankton consume the phytoplankton), indicating that an increase in phosphorus levels increases phytoplankton and bacterioplankton correspondingly (Kisand et al 2001). As discussed in section 5.1, an increase in these microorganisms can be incredibly harmful to the coinciding habitat and marine environment.

A perhaps even more pivotal observation in the study is the elimination of water turbidity and particle evidence. This suggests that the organisms are not only taking the harmful chemicals out of the water, but also the harmful bacteria and plankton that are thriving off of the chemicals. Tropical Demosponges, such as the proposed species, feed off of microorganisms, organic particulates and bacterioplankton (Holmes 2000), which cause turbidity in the water and threaten the ability of the photosynthesizing organisms such as seagrass and coralline algae to photosynthesize and oxygenate the seawater, which is an imperative ecosystem service. When the sponges and oysters filter the water of these destructive microbes, they are thereby indirectly assisting marine photosynthesis. A European study completed in 2006 concluded that in one hour a $1-\mathrm{m}^{2}$ patch of sponges could retain up to $7 \times 10^{10} \mathrm{E}$. coli cells through a filtration of 14 liters of seawater (Gifford et al 2006). E. coli are bacteria cells that are contained directly in the effluent runoff and can be deadly to humans if ingested, not to mention the damage done to other consuming species. It has been found that, in some places, benthic sponges may even thrive closer to an enrichment source (Holmes 2000). The idea that sponges can filter and retain these cells proves them to be vital to a remediation process for both humans and the surrounding impacted ecosystems.

Fortunately, marine sponges are abundant and highly diverse around Zanzibar. The species under investigation is in the class Demospongiae, which is highly adaptable, proven through the observation of their ability to regenerate their pinacocyte (analogous to epidermis) tissue after explantation and continue to expand their mass and volume of each explant, all from the same original organism. This was evident in both the observations of the farmed sponges and the collected sponges of Jambiani, Unguja. Sponges collected for the filtration experiment had covered the spongocoels and choanocytes (inner anatomy exposed from cutting) with pinacocytes by the second day of study. These examples display their adaptability to 
morphological manipulation and therefore their ability to successfully survive and grow throughout explantation.

Similarly to sponges, oysters provide an ecosystem service to their benthic habitats through filtering the surrounding water column. Oysters are mollusc invertebrates that obtain nutrition from oxygenated seawater as it is delivered to their gills. Both P. fuctata and P. radiata species suggest that oysters feed nonselectively, meaning through the filtration of seawater for a microalgal food source, the species filter the entire surrounding water column of particulate matter (Gervis and Sims 1992). Another study performed in Australia on P. imbricate indicated that one ton of oysters could filter $7.5 \mathrm{~kg}$ of nitrogen and $0.55 \mathrm{~kg}$ phosphorus (Gifford et al 2005). Such findings are strong representations of the power oysters have in seawater nutrient remediation, particularly in large populations.

The filtration experiment supports this data in showing the significant decrease in phosphate concentration of the seawater samples after the filtration periods. In comparison to the $3.93 \mu \mathrm{g} / \mathrm{L}$ phosphate concentration of the contaminated water, the average concentration after oyster filtration of the seven replicates was $1.73 \mu \mathrm{g} / \mathrm{L}$ (see figure 1 in section $4.3 \mathrm{~b}$ ). Similarly to the sponge, this indicates the effective uptake of the destructive phytoplankton population in the seawater, and therefore the pivotal ecosystem service the oysters provide.

As indicated in the Australian study, the oysters are also distinguished accumulators and curators of nitrogen levels. The sharp increase in the concentration of the ammonium dissolved in the seawater is an indication of dissolved nitrate remediation and eutrophication prevention. The average ammonium concentration in the contaminated seawater is $4.01 \mu \mathrm{g} / \mathrm{L}$ while the average concentration after the filtration experiment is $21.5 \mu \mathrm{g} / \mathrm{L}$. This sharp increase is suggested to be caused by the remediation of nitrates given that dissolved nitrogen exists in seawater in one of the two forms. With the acute increase in ammonium concentration across replicates (see figure 2, section $4.3 \mathrm{~b}$ ), the oysters are evidently accumulating the nitrates in the seawater and releasing the source as ammonium to a dominant degree. Oysters contain symbiotic bacteria in their gills that perform this denitrification, providing the oysters with the oxygen gas byproduct (Raj 2008). Accordingly, the oysters actually need a certain concentration of nitrates in the water and therefore it is advantageous to the organisms to out-compete the sediment bacteria (highly concentrated in mangrove stands) for the nitrogen source, thereby indirectly preventing that anoxic process. While the surge in ammonium concentrations are admittedly not much more ideal for the aquatic environment, the substance can at least be treated by a simpler organism. The project by Lindell in the United States utilizes the high concentrations of ammonium to grow seaweed near the oyster farms (Saito 2012). Thus it could be advantageous to continue this study by including seaweed as a tertiary remediation source, which would contribute further to the idea of a holistic ecosystem-based management approach. Ultimately, oysters are suggested as uniquely effective nitrate remediation for polluted seawater filtration.

While the sponges are unique in the strength of their dissolved particle retention, oysters have some retention ability as well. The study completed in 2006 for the journal Trends in 
Biotechnology supports these findings, showing both that oysters reduced effluent presence of nitrogen and phosphorus (by $72 \%$ and $86 \%$ respectively,) but also the turbidity due to chlorophyll a concentrations (Gifford et al 2006). Chlorophyll a is what accumulates when microalgae and bacteria overpopulate, disallowing photosynthesizing organisms to use the compound for energetic processes. The turbidity remediation by both the sponges and the oysters studied could have been more effectively quantified with a total dissolved organic carbon test. However, due to lack of time and lab resources, the test could not be completed in the study period. This obstacle was overcome using simple visual observation, permitted by the incredible filtration abilities of the two organisms.

\subsection{MARICULTURE FEASIBILITY AND IMPLEMENTATION LOGISTICS}

The filtration abilities of both the sponges and the oysters are clear and indispensable, and the idea that they can be farmed could provide incentive for implementation. The mariculture farming practices of both bath sponges and pearl oysters require regular maintenance and monitoring, but comparatively inexpensive and uncomplicated supplies with accessible nearshore locations. Advantageously, both methods require similar supplies, which can be made and sold locally, adding even more of an economic stimulus from the two mariculture implementations. In the same way, the market for the products must be accessible to the local populations for the farming techniques to be practical. The organisms of this study were not only chosen because of their premier filtering skills with an economic incentive provided to local communities, but also decisively because they are not cultivated for consumption purposes. In spite of this precaution, the organisms must be prudently processed to prevent reintroducing the same pollutants they filtered in the first place. A novel Japanese bivalve farm created a process for removing cadmium from the mollusc meat where the cadmium is recycled and reused by a car battery plant to make fertilizer (Gifford et al 2006). This progressive innovation for the waste material is a representation of the further research that is needed regarding the proper disposal or further remediation of the polluted waste from these proposed cultivation techniques. Both farming techniques provide a significant economic stimulant to the local community on multiple levels, and that is an extremely important aspect in the consideration of implementing a new project in Zanzibar.

With progressing pollution issues, immediate action is necessary to prevent any further damage to the human habitation and marine life of Zanzibar's coastline. Through the study of the pollution situation, the proposed organisms' filtration abilities, and the cultivation logistics it is evident that the implementation of these systems could actually be possible with proper management and organization. The proposed techniques are supported by the definitions of ecosystem-based management and integrated coastal zone management, which are both viable strategies for environmental planning and policy. From the study of Marine Cultures and the interview with Christian Vauterlaus it is apparent that the experimental sponge mariculture is progressing successfully and has great potential for the village of Jambiani.

The study of the Department of Environment's involvement with pollution remediation efforts provided an insight into the steps for the proposed implementation. In conjunction with 
the environmental policy of 1996 , it is evident that the department is not particularly involved in the creation of policy, but is active in identifying environmental stressors and proposing solutions. The National Environmental Policy for Zanzibar (1996) states that Integrated CoastalZone Management should be used as a framework, and that efforts should pay particular attention to pollution degradation to coral reefs and mangrove stands. It also emphasizes community participation in environmental management, and asserts that environmental legislation should be drafted in support of pollution control and environmental health. By these standards, the proposed project is the ideal primary solution to the pollution situation given that it is taking an integrated approach through a holistic ecosystem viewpoint directly involving and benefiting the local community. Implementing bath sponge and pearl oyster farming for the remediation of polluted waters could be promoted and aided by the Department of Environment through further community outreach and education, legislation enactment, and funding opportunities. Ecosystem-based management is a format for handling environmental issues which calls attention to the entire system: what is taken out, what is put in, and the indirect services the system provides (Mohammad, personal communication), which is appropriate for the implementation of the bath sponge and pearl oyster filtration mariculture given the fact that the proposed remediation techniques treat the pollution using a natural member of the ecosystem. EBM highlights the connectivity within ecosystems, between ecosystems, and with the human population.

With a hypothetical implementation of the proposed techniques, the location is a pivotal aspect, which indicates that the shores of Maruhubi and/or Mtoni are prime locations for remediation. Seawater at this location is far enough away from both the traffic of Stone Town and the intensity of sewage outflows (see figure 5, Van Bruggen map, of Appendix I). The formation of this coastline is also ideal because its shallow depth allows access to the community to the potential locations of the mariculture farms. The seawater deflected off the Stone Town peninsula would pass through these actively filtering waters before reaching the fringing reefs or the feedback water circulation system (see diagram in figure 4 of Appendix I). These logistics are vital considerations in the implementation of the mariculture for pollution remediation.

\section{CONCLUSION AND FUTURE RECOMMENDATIONS}

Bath sponge and pearl oyster farms are suggested as feasible natural pollution filtration systems for the remediation of the seawater off the coast of Stone Town, Unguja. These coastal waters have displayed high concentrations of pollution since investigation began in the 1990s. With a lack of proper planning for the runoff system in the growing urban center, raw effluents have been consistently discharging into the coastal seawater since the city's emergence, gaining strength with the surge in population in recent decades, and noticeably impacting the fringing keystone coral reef and mangrove ecosystems along with human populations. Raw effluents carry dissolved nutrients, such as nitrates and phosphates, toxic microorganisms, such as fecal coliform bacteria, and dissolved organic compounds. The nutrients cause overpopulation of naturally occurring microorganisms in the water column, which creates inhabitable conditions 
for other organisms. The fecal bacteria can carry deadly diseases to the human populations and can be toxic and deleterious to the species in the affected ecosystems.

Detrimental affects of pollution strongly advocate for the establishment of techniques to decelerate the environmental degradation. This study displayed a glimpse into the unique filter feeding abilities of the powerful marine sponges and oysters, displaying phosphate accumulation and indicating filtration of phytoplankton overpopulation. Marine sponges exhibited a unique ability to retain suspended particulate matter through the turbidity observations, while the oyster analysis suggested a unique ability to remediate nitrate levels through chemical transformation, both of which are supported by literature. This proposal is in extremely theoretical and experimental stages so for responsible and effective implementation of the proposed techniques, further research needs to be completed. In terms of the filtration abilities of the organisms studied, nitrate and dissolved oxygen analyses would further support the data on their ability to effectively filter the pollution. Additionally, varying concentrations of the contaminated seawater in relation to the organism replicate filtration rate/quality would indicate the organisms' tolerance to pollution levels.

In conjunction with the filtration abilities of the organisms, the research on the farming accessibility on the island of Zanzibar suggests that implementing the mariculture as a pollution filtration system could be highly effective. Collaboration would be highly effective to initiate the remediation, including the consultation by the organizations that are already experimentally practicing the farming techniques around the island, the management and aid of the applicable governmental sectors, the education and participation of local communities, and the continuance of scientific research by the Zanzibar Institute of Marine Science. A key future study, however, would be the contaminant level of the living tissue that is disposed of after cultivation and techniques to recycle or neutralize these potential waste products.

Implementing ecosystem-based filtration techniques for the remediation of polluted seawater off the coast of Stone Town is a prudent action in protecting the health of the human population and the environment. The techniques would not only benefit the ecosystem by catching the toxic water before it enters the ecosystems, but also before it enters the feedback water circulation eddies, bringing the pollution back to the surrounding coastal inhabitance. With further research, the proposed project has the ability to benefit the environment and the human population simultaneously, while slowing the harmful effects of the pollution inputs.

\section{ACKNOWLEDGEMENTS}

This study involved the support of many individuals and organizations. The Institute of Marine Science Zanzibar hosted the experiment and provided contact with the Fumba pearl oyster project. Dr. Aviti J. Mmochi provided an exceptional knowledge about, attention to and interest in this study. Marine Cultures (marinecultures.org) and Christian Vauterlaus represent the innovation in local opportunities, the like of which keeps the islands of Zanzibar so unique. The SIT Zanzibar staff delivered excellent support in contacts, logistics and commitment. Fellow SIT students contributed motivation power, but more importantly humor and sanity. 


\section{WORKS CITED}

Anderson, B. (1994) An environmental monitoring approach to sewage pollution issues along the west coast of Zanzibar. Unpublished undergraduate. School for International Training.

Duckworth, A.R. and Wolff, C. (2007). Bath sponge aquaculture in TS, Australia: Effect of explant size, farming method and the environment on culture success. Aquaculture, 271(14), 188-195.

Friday, S. (2011.) A study of sponge aquaculture in Jambiani: Is shallow farming feasible? Unpublished undergraduate. School for International Training.

Gervis, M.H. \& Sims, N.A. (1992.) The Biology and Culture of Pearl Oysters (Bivalvia: Pteriidae.)

Gervis, M.H. \& Sims, N.A. (1992.) The Biology and Culture of Pearl Oysters (Bivalvia: Pteriidae.)

Gifford, S., Dunstan, R.H., O'Connor, W., Koller, C.E., \& MacFarlane, G.R. (2006). Aquatic zooremediation: deploying animals to remediate contaminated aquatic environments. TRENDS in Biotechnology, 25(2), 60-65.

Jiddawi, Narriman. 8 April 2013. Pearl oysters and previous remediation efforts interview. Instistute of Marine Science. Personal communication.

Kisand, V. Tuvikene, L., \& Noges, T. (2001). Role of phosphorus and nitrogen for bacteria and phytoplankton development in a large shallow lake. Hydrobiologia, 457(2001), 187-197.

Longo, C., Corriero, G., Licciano, M., \& Stabili, L. (2010). Bacterial accumulation by the Demospongiae Hymeniacidon perlevis: A tool for the bioremediation of polluted seawater. Marine Pollution Bulletin, 2010(60), 1182-1187.

Milanese, M., Chelossi, E., Manconi, R., Sara, A., Sidra, M., \& Pronzato, R. The marine sponge Chondrilla nucula Schmit, 1862 as an elective candidate for bioremediation in integrated aquaculture. Biomolecular Engineering, 20(2003), 363-368.

Mmochi, A.J. (1996). Marine Pollution on Zanzibar \& Tanzania. Institute of Marine Sciences Zanzibar. University of Dar Es Salaam.

Mohammad, Salim. Ecosystem-Based Management in the Coastal Area. Institute of Marine Science, Zanzibar. Personal communication.

Moynihan, M. (2011). Water Quality and Eutrophication: the effects if sewage outfalls on waters and reefs surrounding Stone Town, Zanzibar. Unpublished undergraduate. School for International Training. 
National Environmental Policy for Zanzibar for the Zanzibar Revolutionary Government. Commission for Lands and Environment \& Ministry of Water, Construction, Energy, Lands and Environment. (1992).

National Oceanic and Atmospheric Administration. (2013). "Dead Zone" is a more common term for hypoxia, which refers to a reduced level of oxygen in the water. <http://oceanservice.noaa.gov/facts/deadzone.html>

Nyandwi, Ntahondi. 18 April 2013. Zanzibar current patterns interview. Institute of Marine Science. Personal communication.

Parsons, T.R., Maita, Y., \& Lalli, C.M. (1984.) A Manual of Chemical and Biological Methods for Seawater Analysis. Pergamon Press. University of Wisconsin-Madison.

Parsons T.R., Takagashi, M., \& Hargrave, B. (1985.) Biological Oceanographic Processes (3 ${ }^{\text {rd }}$ ed.) Pergamon Press. University of Michigan.

Raj, P.J.S. (2008). Oysters in a new classification of keystone species. Resonance. Chennai, India.

Rijaal, Hamza. 18 April 2013. Department of Environment Interview. Personal communication.

Saito, E. (2012, Fall). The Good (Sea)Weed. Edible Cape Cod 31-32. Retrieved from the Woods Hole Oceanographic Institute fileserver.

Shunula, J.P. and Ngoile, M.A.K. (1995). Consequences of Human Activities on the Marine Environment of Zanzibar. Institute of Marine Sciences Zanzibar. University of Dar Es Salaam.

Souza, F.M., Brauko, K.M., Lana, P.C., Muniz, P., \& Camargo M.G. (2013). The effect of urban sewage on benthic macrofauna: A multiple spatial scale approach. Marine Pollution Bulletin, 67(2013), 234-240.

Progress in Integrated Coastal Management for Sustainable Development of Zanzibar's Coast: Unguja Island Coastal Profile and Management Strategy, section 7 for the Zanizbar Revolutionary Government. U.N. Environmental Programme, FAO, Swedish International Development Agency, \& East African Regional Seas Technical Reports. Split, Croatia: Priority Actions Programme (2000).

Van Bruggen, J.J.A. (1990) Preliminary Study on Environmental Pollution on Zanzibar. University of Dar Es Salaam. Department of Environment. Commission of Lands and Environment. Zanzibar Integrated Land Use Project of FINNIDA.

Vauterlaus, Christian. 15 April 2013. Marine Cultures Interview. Marineculutres.org. Personal Communication. 


\section{APPENDIX}

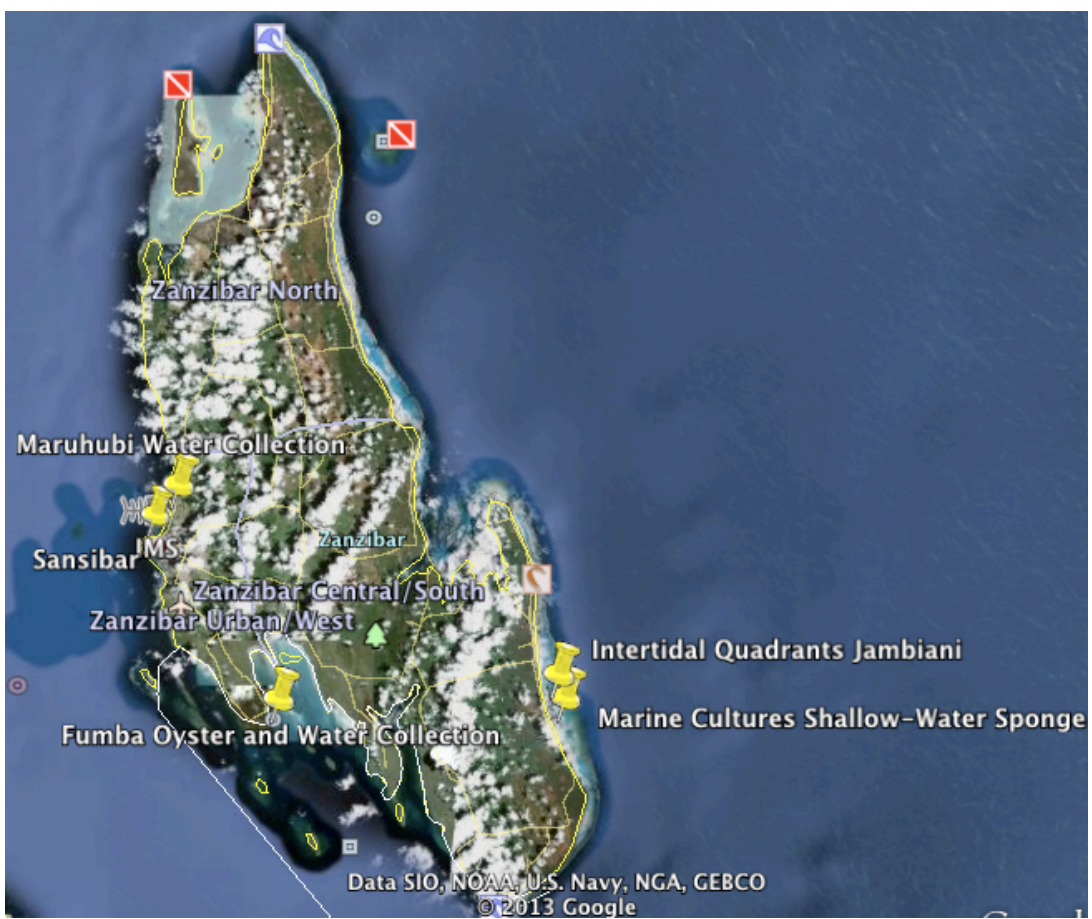

Figure 3. Zanzibar Ungujaa Island with study area markers. (GoogleEarth, 2013)

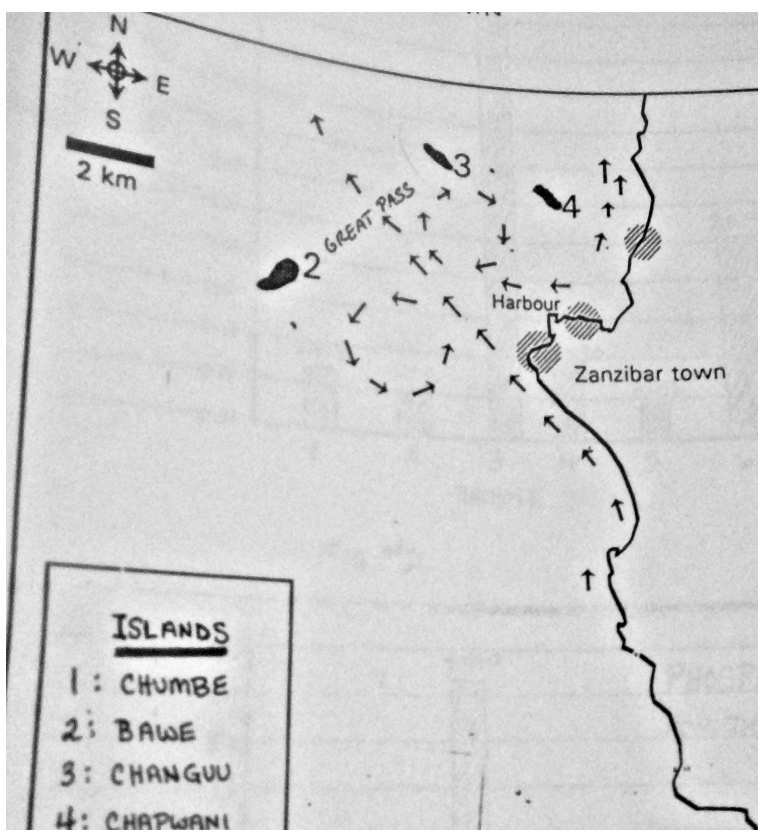

Figure 4. Urban Zanzibar seawater current system (Anderson: 1994). 


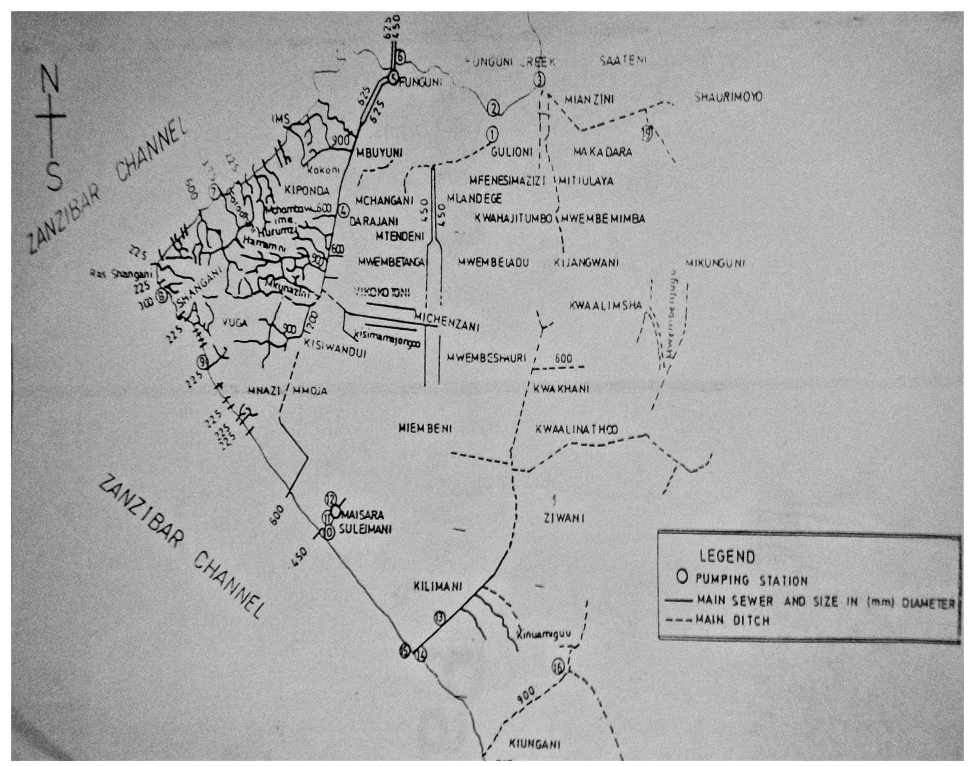

Figure 5. Stone Town runoff system. (Van Bruggen 1990). 